\title{
Modeling of Inhibition Mechanism of Natural Ligands to Farnesyl Protein Transferase Using Molecular Docking
}

\author{
Nack-Do Sung, Young Gu Cheun, ${ }^{\dagger}$ Byung-Mok Kwon, ${ }^{\ddagger}$ Hyung Yeon Park, ${ }^{\$}$ Chan Kyung Kim ${ }^{5 . *}$ \\ Division of Applied Biolog: \& Chemistry, Chungnam National Liniversity. Daejeon 305-764. Korea \\ Agency for Defense Development. P.O. Box 35, Yuseong, Daejeon 305-600 Korea \\ ${ }^{+}$Korea Research Instithte of Bioscience and Biotechnolog;, P.O. Box 115, Yuseong, Daejeon 305-600, Korea \\ ${ }^{\$}$ Department of Chemistry: Inha liniversity; Inchon 402-751, Korea \\ Received .huly 29,2003
}

Key Words : Molecular modeling, Farnesyl protein transferase inhibitor, Molecular docking

Ras Proteins play important roles in the signal transduction necessary for the cell growth. In the tumour cells, approximately $30 \%$ of the Ras protein genes are mutated. Ras proteins $(H, N$, and $K$ ) are small guanine nucleotide binding proteins that undergo a series of post-translational modifications including the farnesylation on the thiol group at the Ras C-terminus catalyzed by the farnesyl protein transferase (FPTase), ${ }^{2}$ This is a mandatory process before anchoring to plasma membrane which is critical for its biological activity, e.g. cell proliferation and tumorigenesis. Recent work has demonstrated that specific inhibition of the FPTase might be interesting to find effective therapeutical agents for the treatment of cancer. ${ }^{3}$

Many synthetic FPTase inhibitors have been tested including peptidomimetics in the past few years. However, a few examples of natural products inhibitors were reported. In a recent work, many natural ligands were isolated as possible inhibitors of F.PTase. "In the course of their screening for protein inhibitors from herbal medicines, several compounds including arteminolide A (1) and artenomaloide $B$ (2) were reported. I was identitied as a configurational isomer of 2.1 strongly inlibited FPTase $\left(\mathrm{IC}_{50}=0.36 \mathrm{M}\right)$ but 2 inhibits weakly $\left(\mathrm{lC}_{\mathrm{5}}=200 \mathrm{M}\right)$.

\section{Molecular Modeling}

In this work, molecular docking studies between a biomacromolecule and $\mathbf{1}$ or $\mathbf{2}$ were performed in order to identify their biological activity differences using the modules implemented in the molecular modeling package SYBYL. ${ }^{5}$ The FPlase protein (code name: IQBQ) used for the docking is available from the Protein Data Bank. ${ }^{6}+\mathrm{P}^{3}$ [ase is a zinc heterodimeric metalloenzyme complexed with farnesyl pyrophosphate (FPP) and $\mathrm{Ca}_{1} \mathrm{a}_{2} \mathrm{X}$ consensus motif, where $\mathrm{a}_{1}$ and $\mathrm{a}_{2}$ are aliphatic amino acids and $X$ can be any residue, at $2.5 \AA$ resolution.

In an extensive docking study ${ }^{7}$ using Biodock program, four different binding modes were postulated depending on the physicochemical properties of natural ligands: (1) Non

\footnotetext{
"To whom correspondence should be addressed. Tel.: +82-32860-7684; E-mail: kckyung(a)inha.ac.kr
}

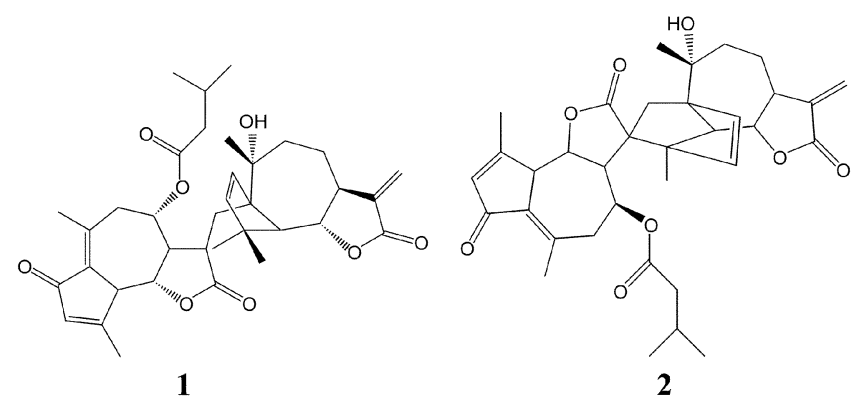

specific (2) $7 \mathrm{n}^{2-}$ shielding (3) Peptidomimetic (4) FPPmimetic. If a natural compound has molecular volume similar to that of $\mathrm{Ca}_{1} \mathrm{a}_{2} \mathrm{X}$ motif, it can inhibit the FPTase occupying selectively the binding site of peptide substrate, and thus can be defined as a peptidomimetic inhibitor.

\section{Results and Discussion}

Molecular volumes ${ }^{8}$ and $\log P$ values of $\mathrm{Ca}_{1} \mathrm{a}_{2} \mathrm{X}$ motif, FPP, 1, and 2 were calculated using the Sybyl package and the results are summarized in Table 1 . Inspection of Table 1 shows that the two ligands considered in this work have twice larger volume than FPP but have volumes similar to the peptide motif. The $\log \mathrm{P}$ values are slightly greater than that of $\mathrm{Ca}_{1} \mathrm{a}_{2} \mathrm{X}$ motif. This means that $\mathbf{I}$ and $\mathbf{2}$ can occupy the same binding site as the peptide substrate but with slightly different orientations.

Recently, several methods for the docking of a ligand to an enzyme have been developed and tested. ${ }^{10}$ HlexX is one of the methods and is successfully applied to predict numerous

Table 1. Molecular volumes" (in $\mathrm{cm}^{3}$ ) and log $\mathrm{P}$ values" tor Selected Molecules

\begin{tabular}{lcc}
\hline Molecule & Volume & log $\mathrm{P}$ \\
\hline $\mathrm{Ca}_{1} \mathrm{a}_{2} \mathrm{X}$ & 474.0 & -1.4 \\
FPP & 271.6 & 4.8 \\
compound 1 & 442.7 & 2.4 \\
compound 2 & 472.9 & 2.9 \\
\hline
\end{tabular}

"Molecular volumes are calculated using the method described in rel. 8 . 'Log ?' values ate calculated using the method described in ret.' 9 . 


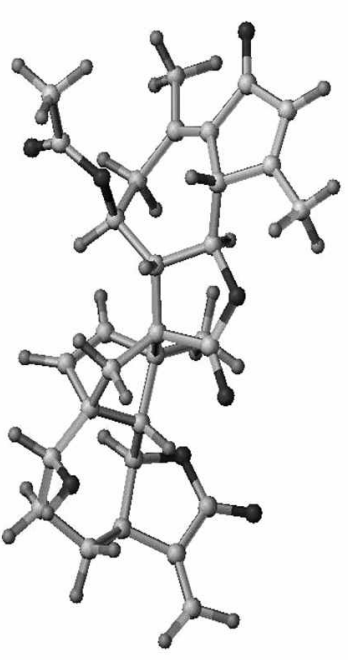

(a)

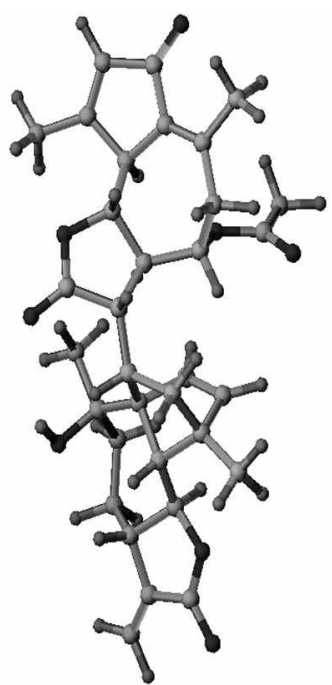

(b)

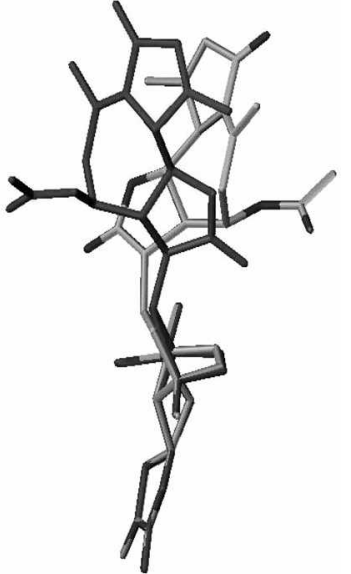

(c)

Figure 1. Three-dimensional structures of two ligands considered in this work. (a) compound 1 (b) compound 2 (c) Compounds 1 and 2 are superimposed to see their structural differences.

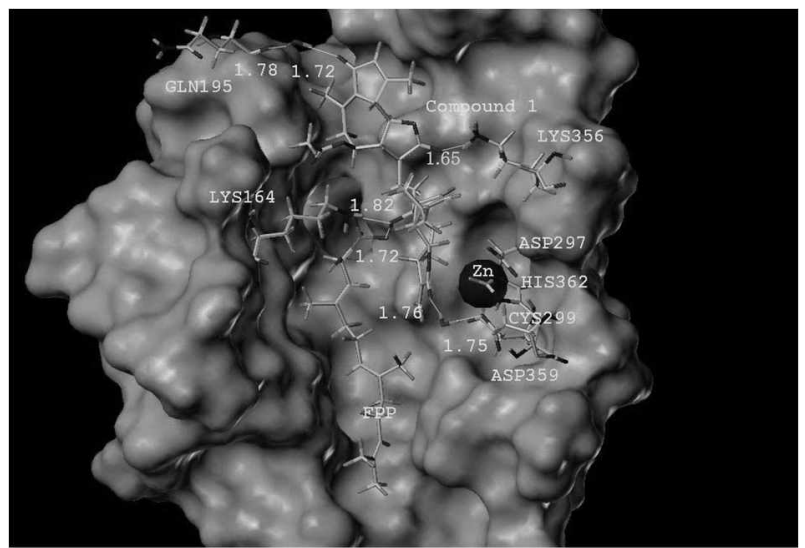

(a)

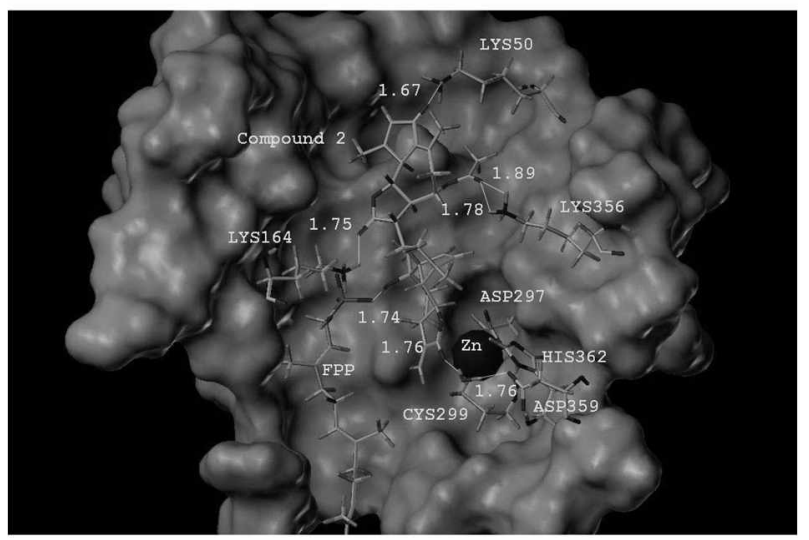

(b)

Figure 2. Hinal optimized docked structures between FHTase and natural compounds considered in this work. (a) Main interactions between conpound 1 and FPTase. (b) Main interactions between compound 2 and HPTase.

X-ray crystallographic structures of enzyme-substrate complexes. ${ }^{13}$ All ligands structures were minimized using the

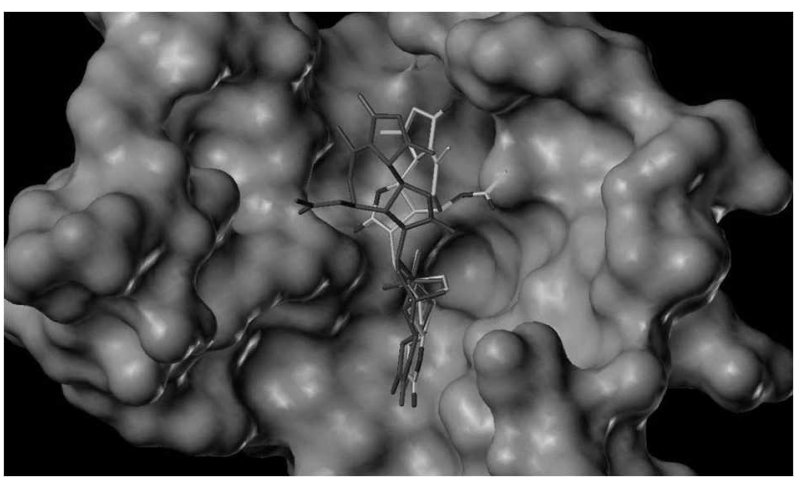

Figure 3. Superimposed image of two docked structures between 5 PTase and compound 1 or 2 . Compound 1 is in purple color and compound 2 is in original ball \& stick color. This picture clearly shows differences in binding modes between two ligands.

Tripos force field ${ }^{12}$ until RMS gradient was less than 0.05 . The charge of $\mathrm{Zn}^{2+}$ was set to +2 and the Ca $\mathrm{a}_{2} \mathrm{X}$ motif was removed for ligand docking. Fully optimized three-dimensional structures of $\mathbf{1}$ and $\mathbf{2}$ are shown in Figure $\mathbf{l}$ along with the superimposed image of two structures to examine their structural differences. Docking experiments were done using the FlexX module and the final structures were subjected to minimization until RMS gradient was less than 0.05 keeping all residues $15 \AA$ farther away from the active sites fixed. In the first experiment. all water molecules were removed from the X-ray structure initially. But this result was not realistic because the position of $\mathrm{Zn}^{2+}$ ion is far moved from its original position. In the second experiment, all water molecules were included in the docking study. Ligands 1 and 2 could bind to the same position previously occupied by the $\mathrm{Ca}_{3} \mathrm{a}_{2} \mathrm{X}$ motif and final minimized structures are shown in Figure 2.

In the docking structure of 1 to FPTase (Figure 2(a)), 1 forms three strong hydrogen bonds - two with Ly'sl64 (bond 
length $=1.82 \AA$ ) and Lys 356 (bond length $=1.65 \AA$ ) located in the pocket entrance and the other with the FPP (bond length $=1.72 \AA$ ) - and additional hydrogen bonds with Asp359 and Gln 195 mediated by water molecules. This structural feature is similar to the inhibition mechanism found in the crystal structure - the thiol group in the Cys of $\mathrm{Ca}_{1} \mathrm{a}_{2} \mathrm{X}$ motif blocks the binding between $\mathrm{Zn}^{3+}$ and FPP. Three-dimensional orientation of two ligands is different only at the top part as shown in the superimposed image of Figure I(c). This structural difference suggests that 2 bind to the same way as 1 in the case of lower part of the ligand but to different orientation in the case of top part. 2 also binds to the position previously occupied by the $\mathrm{Ca}_{1} \mathrm{a}_{2} \mathrm{X}$ motif and forms strong hydrogen bonds with Lys50. Lysl6t and Lys356. Similarly. water bridged-hydrogen bond with Asp359 is also found. To get a clear view of the docking structures, two docked structures are superimiposed in Figure 3. One can see that both $\mathbf{1}$ and $\mathbf{2}$ form hydrogen bonds with Lysl6t and Lys356 residues. Structural difference in the interaction mode with FPTase is that $\mathbf{1}$ interacts with some residues at the entrance but $\mathbf{2}$ does not. Different modes of binding are reflected in the final binding energy of two docked structures $(-9.15 \mathrm{kcal} / \mathrm{mol}$ for 1 -FPTase is -1.03 $\mathrm{kcal} / \mathrm{mol}$ for 2-FPTase) ${ }^{13}$ which is in line with the experimental biological activity differences between $\mathbf{1}$ and $\mathbf{2}$.

Acknowledgement. This work was financially supported by a grant (R01-2000-000-00153-0) from the Korea Science and Engineering Foundation. This work was also supported by the Brain Korea 2l Project in 2003. One of us (Park. H. Y.) also thanks for a university postdoctoral position.

\section{References}

1. Schafer. W. R, Kim. R.; Sterne, R.: Thorner, J.: Kim, S. H.: Rine. J. Science 1989. 245.379

2. Stimmel. J. B.: Deschenes. R. T.: Volker. C.: Stock. J.: Clarke. S Biochemism 1990. 29.9651.

3. Porfiri. E; Evans. T.: Chardin. P.: Hancock, J. F. J. Biol Chent 1994. 269,22672

4. (a) Lee. S.; Kim, M.: Bok. S. H.: Lee, H, Kwon, B.: Shin. J.: Seo. Y. J. Org Chem 1998. 63. 7111. (b) Lee. S.: Kim. H.: Seo. T.: Kang. H.: Kim. J. H.: Son1. K.: Lee. H.: Kwon1. B.: Shin. J.: Seo. Y. J. Ong Chent 2002. 67.7670.

5. SYBIL nolecular modeling sofmare', Tripos Ine: 1699 South Hanley Rd. Suite 303. St. Louis. MO 631 t4.

6. Strickland, C. L.; Windsor, W. T; Syto, R.: Wang, L.: Bond. R.: Wu. Z.: Schwartz. T.: Le. H. V.: Beese. L. S.: Weber. P. C. Biochemistry 1998. 37.16601 .

7. Pedretti. A.: Villa. L.: Vistoli. G. J. Med Chent. 2002. 45. 1460.

8. (a) Richards. F. M. Am Ren: Biophws. Bioeng. 1977, 6, 151. (b) Hermann. R. B. J. Pliss. Chem. 1972. 76, 19.

9. (a) Ghose, A.: Crippen, J. P. Comp. Chem. 1986, 7(4), 565. (b) Viswanadhan. V. N.: Ghose. A. K.: Revankar. G. R.: Robins. R. K J. Chem. Inf. Comput Sci. 1989.9.163.

10. (a) Rarey. M.: Kramer. B.: Lengauer. T.: Klebe. G. J. Mol. Biol. 1996. 261, 470. (b) Rarey. M.: Wefing. S.; lengauer. T. J. ComputAided Hol. Design 1996. 10. 41

11. (a) Jacek. S.: Markus. B.; Isabel, S.; Hans-Martin, D.; Martin, D. J. Hed Chem 2001. 44. 2886. (b) Rarey. M: Kramer. B.: Lengauer. T. Bionfon hatics 1999. 15. 243.

12. Clark. M.: Cramer. R. D.. III: Van Opdenbosch. N. J. Conp. Chent $1989,10,982$.

13. In general, it is impossible to compare stabilities of two compounds based on the force field energy. However, this is only true if the two structures are conformers or configurational isomers. See Rapp. A. K.: Casewit. C. J. Holecular Mechamics across Chentistry: University Science Books: California. USA. 1997: p 25. 